\title{
Escondendo os "1\%": crítica e lógica socioculturais
}

Roberto Grün'

\section{Resumo}

O Brasil é considerado como um dos países de distribuição de renda mais desigual no mundo contemporâneo. Entretanto, nele não emerge nenhuma crítica social específica da assimetria de recursos materiais. $\mathrm{O}$ artigo discute algumas hipóteses para explicar essa realidade aparentemente ilógica. Responde fundamentalmente pela dependência de caminho da afirmação da crítica da assimetria de recursos culturais e vincula esta última à emergência dos principais grupos políticos que surgiram com a redemocratização de 1985 e cuja dinâmica de disputa política segue uma lógica cultural. A disputa cultural subsome o potencial contencioso econômico, pois se instala duravelmente como sistema de metáforas, dotado de "dureza simbólica".

Palavras-chave: Sociologia dos intelectuais. Sociologia das finanças. Sociologia dos escândalos. Sociologia da crítica. Desigualdades sociais.

\section{Introdução}

Nos últimos 30 anos, vimos se desenvolver uma sociologia da crítica envolvendo a análise direta da construção de objetos para a crítica social, ambiental, religiosa, de gênero e outras. Apoiando-se em Wittgenstein, ela explora a diferença entre o "mundo" e a "realidade" (WITTGENSTEIN, 1961; BOUVERESSE; ROSAT, 2000). O primeiro sendo o enorme repertório de possibilidades existentes para a construção de percepçóes sobre a sociedade e a segunda, as possibilidades efetivamente aproveitadas

I Mestrado em Ciências Sociais pela PUC-SP (1985), Doutorado em Ciências Sociais pela UNICAMP (1990), com estágio de complementação do doutoramento na Écoles des Hautes Études en Sciences Sociales (1989). Foi "Directeur de Recherches" da Fondation Maison des Sciences de l'Homme, "Directeur d'Etudes" da École des Hautes Études en Sciences Sociales e "Joaquim Nabuco Chairman in Brazilian Studies" na Universidade de Stanford.

Direito autoral e licença de uso: Este artigo está licenciado sob uma Licença Creative Commons. Com essa licença você pode compartilhar, adaptar, para qualquer fim, desde que atribua a autoria da obra, forneça um link para a licença, e indicar se foram feitas alterações. 
para a construção das configurações perceptíveis. Em seguida, a exploração sistemática dos factíveis, justamente por meio da crítica, e o passo subsequente, a crítica de segundo grau, incidindo sobre essas operaçóes cognitivas e sociais que produzem a problematização da sociedade (BOLTANSKI; CLAVERIE; OFFENSTADT, 2007; BOLTANSKI, 2009, 2012 , 2014). Essa perspectiva pode ser útil para a sociologia dos intelectuais, dirigindo a nossa atenção para a criação de objetos críticos e explicando a não existência de outros, que seriam esperados em um espaço social e cultural "racionais", mas que não emergem na situação concreta do Brasil contemporâneo.

Diversas desigualdades percebidas analiticamente pelos intelectuais brasileiros não se transformam em objeto de debates na esfera política, enquanto outras saliências o são, mesmo quando parecem "menos graves" dos que as primeiras. Há, portanto, uma dissociação entre a lógica que cria a sensibilidade dos cientistas sociais envolvidos nas pesquisas científicas e agentes sociais e políticos que tentam patrocinar causas que consideram de interesse público e as lógicas que emergem nos espaços cultural e político da sociedade. Explorar essas divergências pode ser uma boa entrada para o reconhecimento de algumas especificidades da sociedade brasileira contemporânea, uma vez que o que acontece nos dois últimos espaços reflete muito diretamente a dependência de caminho para as possibilidades e impossibilidades do presente e do futuro do País. E, implicitamente, também convida a ciência social que se ocupa dele a levar em conta essa dimensão, que chamamos provocativamente de "dureza da realidade simbólica", para dar conta das dinâmicas realmente existentes na sociedade brasileira.

\section{Os I\% no Brasil: quem? Quais?}

No início da segunda metade da década de 2010 houve uma grita internacional contra os $1 \%$ privilegiados da atual ordem econômica. No Brasil, mesmo na década de imensa polarização política e ideológica que transcorreu durante os governos petistas, especialmente depois do mensalâo em 2004-2005, pouco ouvimos desse tipo de crítica e, muito menos, achamos clamor popular próximo dessa formulaçáo. Por exemplo, o Instituto Datafolha pergunta, pelo menos desde o início do primeiro governo de Fernando Henrique Cardoso (FHC), quais são os principais problemas 
do País. A questão de desigualdade é sempre indagada, mas na maior parte da série não é sequer mencionada pelos respondentes ${ }^{2}$.

Quais seriam as razóes dessa "jabuticaba”? Quais questóes ela levanta para a sociologia? Nas duas últimas décadas, a tensão internacional, em princípio causada pela financeirização das economias centrais, desaguou em uma figura de crítica bem específica, os $1 \%$ mais ricos, cuja parcela na renda e no patrimônio individual dos países não para de crescer e se tornou motivo de reprovação (KEISTER, 2014; PINÇON; PINÇON-CHARLOT, 2016; KILLEWALD; PFEFFER; SCHACHNER, 2017). De alguma maneira, essa é uma construção lógica, esperada, produzida "naturalmente" pela tensão social causada pela escalada da desigualdade de renda. As estatísticas dizem que ocorreu uma concentração de renda inédita no capitalismo mundial. E, passada a fase aguda da crise financeira internacional de 2008, a situação se intensifica, em detrimento não só dos mais pobres, mas também das camadas de renda média, e não parece infletir para melhor. ${ }^{3}$ Mas seria suficiente a "mera" saliência numérica para constituir o problema ou a sensibilidade social para a questão?

A tentativa de resposta à indagação apresentada permite discutir as relaçóes entre hegemonia econômica, política e cultural, levando-nos a resultados não intuitivos sobre a lógica da dominação social, as formas de imposição dos arrazoados que emanam das camadas dominantes e o assujeitamento dos grupos subordinados na sociedade brasileira contemporânea à realidade social produzida a partir dos enquadramentos cognitivos dessa produção cultural hegemônica.

No automático da percepção social, as figuras que a sociedade e ou parte dela consideram responsáveis pelas suas dificuldades se formam naturalmente. Momentos de polarização política e cultural agudas, como aquela que a sociedade brasileira viveu na primeira metade da década de 2010,

2 Para saber mais, ver: DATAFOLHA (2015, tabelas 42 a 47). Complementarmente, ainda que a edição do Latino-barômetro de 2013 (a última disponivel no momento da redação do texto) registre que 78\% da população brasileira considera injusta ou muito injusta a distribuição de renda desta sociedade, mesmo assim ela também não a elenca como um dos problemas mais graves dentre aqueles que afligem o Brasil. Para saber mais, ver: LATINOBAROMETRO [20/8].

3 Na linguagem jornalística anglo-saxã. "[...] a maré da crise levou os barcos dos ricos, dos pobres e dos remediados para baixo, mas a maré contrária do após-crise só levantou o barco dos mais ricos." (THE ECONOMIST, 2014). 
mostram claramente que o "automático" encobre o essencial das disputas sociais. Especificamente, a construção da dominação.

Diversos aspectos da realidade podem ser percebidos como problemáticos. Esses pontos podem ser diferentes para diferentes grupos sociais ou mesmo para o mesmo segmento da sociedade em momentos diversos. Mas esse aparente relativismo encobre o essencial: alguns pontos são selecionados pela sociedade e se transformam em figuras públicas de crítica. Ao serem alçados a essa situação, passam a ser objeto de disputas. Primeiro pelo seu significado, depois pela maneira de alterar o ponto da realidade visto como problemático. Esse movimento é a construção social da realidade em estado atuante. Representa-se a realidade de uma maneira específica, para depois tentar transformá-la a partir das balizas da representação produzida (HACKING, 1983, 1986). A relatividade ou a indeterminação da situação anterior se desfazem e passamos a um outro estágio, em que a realidade social "endurece", está constituída e dificilmente será refeita ou desfeita (DESROSIĖRES, 1989). Na linguagem mais recente de Boltanski (2009), algumas das diversas possibilidades contidas no mundo acabam se tornando uma realidade.

Nesse sentido, a ereção dos “1\%” em figura da crítica é uma possibilidade contida no mundo contemporâneo. Mas, acrescentemos, há um caminho longo, cheio de desvios e nenhum atalho, entre a possibilidade e a realidade. Estudar esse espaço disputado, por meio das construçóes e desconstruçóes que são estritamente relevantes, no sentido de que fazem ou desfazem relevos perceptíveis é, creio eu, um aporte significativo da sociologia dos intelectuais para a compreensão da política.

\section{A “torre de marfim" e a dura realidade cultural}

Refletindo, no papel, sobre o mundo em que vivemos, diversos cientistas sociais e, especificamente, economistas, levantaram e continuam se indagando por que o problema da "escandalosa" distribuição de renda no Brasil não se constitui em uma questão relevante para a agenda pública em geral, ou política em particular (PAULANI; PASCHOA, 2008). Os números seriam escandalosos neles mesmos e a pouca repercussão dos trabalhos que tentam pô-los em destaque seria em si mesmo um mistério, 
tornando-se, inclusive, um terreno propício para a fabulação de teorias conspiratórias.

Entretanto, "escândalos" não surgem por acaso, como dados de natureza ou como resultado automático da ocorrência dos ultrajes à sociedade ou à natureza medidos ou disparados por um hipotético "indignômetro". Eles têm um lado que nossa linguagem cotidiana chamaria de "estrutural”, que diz respeito às normas existentes que estão, ou estariam sendo desafiadas ou, ainda, novos padróes de sociabilidade e de justiça que estejam em gestação. E têm também uma face ativa, que diz respeito aos indivíduos e grupos que se mobilizam e se articulam visando a promover uma causa conservadora ou transformadora das relaçóes sociais. Escândalos efetivos são aqueles que encaixam as duas faces, e são relativamente raros se pensarmos no número de ultrajes que potencialmente poderiam se tornar escândalos ou transformaçóes que seriam desejadas, mas que foram obliteradas (GUSFIELD, 1986; THOMPSON, 2000; DE BLIC, 2005; GRÜN, 2011).

Claro, há escândalos e "escândalos": o padrão mais próximo do funcionalismo, o escândalo conservador, que chama a sociedade a voltar a respeitar normas tradicionais (DAMPIERRE, 1954), e o escândalo que visa a justamente o contrário, o estabelecimento de uma nova norma social, como aqueles provocados pelas sufragistas, pelos adeptos da temperança em relação ao consumo de álcool e também as feministas e os ecologistas. Atores sociais muito audaciosos costumam provocar os do segundo tipo (GUSFIELD, 1986). Mais do que os primeiros, eles são empreendimentos de risco, pois é necessário criar uma nova sensibilidade para deflagrar a indignação contra a conspurcação da natureza, até então vista como provedora infinita de recursos para a humanidade, ou a favor da igualdade entre os sexos, até então "naturalmente" vistos de maneira hierárquica (CHAMPAGNE, 1984). Não é por acaso que a maior parte dos escândalos mudancistas fracassam no intento de criar novas sensibilidades e institucionalidades. Eles agem contra a inércia social e, por isso, muito raramente são bem-sucedidos (DE BLIC, 2005; GRÜN, 2011).

Nosso "escândalo" da não indignação é um desses casos, mais frequentes, de não criação de escândalo, mesmo se muitos enxerguem razóes mais 
do que suficientes para avocar e tratar a questão moralmente e, indignação instalada e difundida por toda a sociedade, tratá-lo politicamente com chances reais de alterar a situação tida como ultrajante. Não é, assim, por acaso, que a resposta encontrada para a não escandalizaçáo ou é especulativa ou se atém à esfera moral, ou ambas. Nossos indignados e descontentes com a pouca repercussão de sua ação cultural e política são, nesse caso, principalmente empreendedores morais tentando criar uma causa pública, como analisado extensamente por Gusfield (1986) e pelos autores da sociologia da crítica e pragmática (BOLTANSKI; CLAVERIE; OFFENSTADT et al., 2007). Em termos mais analíticos, pretendo aqui mostrar que estamos diante de uma relação de forças simbólica desfavorável aos empreendedores e, especificamente, chamar a atenção para essa "dureza da realidade simbólica”, que manieta seus esforços.

\section{Micro história e cronologia}

O debate sobre distribuição de renda no Brasil que ocorreu na década de 1970 mostrou sensibilidade social para o tema, mas não prosseguiu como causa avocada na pauta política (LEITE LOPES, 1973). Naquele momento, a linha de resistência ideológica dos precursores do mainstream atual era a ideia de "capital humano" como antídoto ou remédio de longo prazo para uma assimetria na distribuição de renda que foi considerada indefensável (LANGONI, 1973). A redemocratização dos anos de 1980 trouxe para a agenda questôes políticas de direitos individuais e coletivos, deixando aquela discussão em fogo brando. Além disso, podemos dizer que, no longo período que durou, até meados dos anos de 2000, simplesmente não tínhamos dados diretos sobre os " $1 \%$ ” porque a riqueza das famílias era estimada por meio da Pesquisa Nacional por Amostra de Domicílios (PNAD), que é declaratória e, por isso, altamente suspeita de induzir subdeclaraçáo de riqueza e renda nos estratos superiores.

$\mathrm{O}$ argumento é deduzido da consideração que os membros das famílias de alta renda provavelmente pagam menos impostos do que deveriam e a exposição da sua riqueza alertaria o fisco dessa falta. Além disso, é apontado o receio desses indivíduos e famílias serem identificados como suscetíveis a assaltos ou sequestros, um arrazoado que continuava convencendo 
os segmentos mais relevantes da sociedade brasileira para a tomada de decisões políticas mesmo em finais de 2016. Uma singularidade brasileira é ele ser mais convincente do que a busca de contemporaneidade nas formas de gestão das empresas e das relaçóes entre elas e o mercado financeiro, pois prevalece duravelmente diante delas.

Em ambos os casos, a subdeclaração diminuiria o risco de um evento não desejado, seja na esfera tributária, seja na criminal. Corretas ou infundadas as razóes dessa "jabuticaba", é fato que no Brasil faltavam os dados das declaraçóes de renda e patrimônio, que eram consideradas sigilosas, ou mal computadas, ou os dois.

Evidentemente, a ausência prolongada desses dados poderia se constituir num problema não só lógico, que impediria a constituição do problema, por meio da publicidade da crítica que a exploração desses dados poderia suscitar, mas também de sociologia do conhecimento e política, pois nos perguntaríamos sobre as causas da náo publicidade de um conjunto de dados obtidos das declaraçóes de imposto de renda, que tecnicamente podem ser disponibilizados, mas não o foram. Outra questáo, também passível de denúncia, é a própria não declaração de renda por parte das famílias mais ricas e a adaptação da estrutura fiscal brasileira a esse "dado incontornável" por meio da taxação mais intensa sobre os salários relativamente mais altos em detrimento de outros tipos de rendimentos, mais ilidíveis, como as remuneraçóes por serviços prestados ou menos ou não taxados como, particularmente, os dividendos de lucro empresarial. ${ }^{4}$ Nominalmente, por causa de problemas ligados ao sigilo bancário e fiscal. E isso na "contramão da história", pois na maior parte dos países nos quais o aparato estatístico do Estado é capaz de fornecer esses dados, foram encontradas maneiras de exibi-los de forma agregada que não expõe indivíduos ou famílias, mas suficientemente desagregada para propiciar a análise.

Entretanto, no Brasil, o argumento do sigilo se sobrepôs, evitando a disponibilização. Interessantemente, para contextualizar a chamada

\footnotetext{
Num registro convergente, os números de 2014, declarados pelos contribuintes à RFB em 2015, mostram que o 0,1\% mais rico da população brasileira - ou 27 mil pessoas num universo de 27 milhões de declarantes do IRPF - afirmaram possuir "apenas" $R \$ 44,4$ bilhões em rendimento bruto tributável de um total de $R \$ 159,7$ bilhões em rendimento total bruto. Portanto, não é demais evidenciar que, da renda declarada desses $0,1 \%$ mais afortunados, apenas 21,75\% é tributável (GOBETTI; ORAIR, 2016; OLIVEIRA, 2017; ONUBR, 2016).
} 
"financeirização" da sociedade brasileira, esse argumento considerado internacionalmente idiossincrático continua se impondo por aqui, sobrepujando consideraçóes sobre a "moderna governança corporativa" e a "necessidade de transparência" que são tidas como condiçóes essenciais para o bom funcionamento dos mercados financeiros e, portanto, de qualquer economia capitalista contemporânea ${ }^{5}$ (GRÜN, 2003). Implicitamente, mas somente no papel, poderíamos afirmar que essa "idiossincrasia" limita as veleidades de atualização do capitalismo brasileiro. Sociologicamente, entretanto, tal consideração não procede, pois os atores brasileiros envolvidos na difusão da "boa governança corporativa" não avocam publicamente nem essa questão nem algumas outras que separam a "nossa boa governança corporativa" daquela prescrita no consenso internacional sobre o assunto. E isso, mesmo que, em termos estritamente analíticos, a questáo salte aos olhos. Ficamos assim diante de mais um exemplo de que a lembrança e o oblívio são cognições sociais muito mais influenciadas pela dinâmica de justificação das hierarquias e equilíbrio de uma determinada sociedade do que o resultado de algum tipo de esclarecimento científico. Ou, mesmo, podemos estender aqui o alcance da afirmação também diante da "necessidade econômica", entendida na objetividade que pretendida pelos seus porta-vozes habituais (DOUGLAS, 1992; GRÜN, 2003).

\section{História cultural e história social}

A análise acadêmica dos 1\% costuma chamar a atenção para "equívocos conceituais" entre rendimento e riqueza; assimetria no seio da pirâmide salarial e de rendimentos em geral, incluindo os rendimentos das atividades empresarias, financeiros e alugueis - a distribuição funcional da renda; miséria e pobreza; a mobilidade social deduzida das relaçóes entre riqueza adquirida e riqueza herdada, dentre outras especificaçôes.

Tais distinções, além de analiticamente necessárias, também têm importância nelas mesmas enquanto "fatos sociais", uma vez que a atenção social mais voltada para cada um dos aspectos isolados, ou nas contraposiçóes, irá gerar figuras de crítica social diferentes. E a crítica bem recebida,

5 Ver: MACHADO e ROCHA (2016) 
no sentido de se tornar base para mobilizaçôes sociais, revela predisposiçóes, pode alterar a realidade de que é fruto e também mostra a especificidade da cultura capitalista desenvolvida em cada formaçáo nacional ou regional em que é testada.

As predisposiçóes podem ser consideradas sensos de justiça a partir dos quais as sociedades constroem argumentos e consensos para aceitar ou rejeitar determinados tipos de aquisição de remunerações e acumulação de riquezas como justas ou como privilégio indevido. A figura engendrada pela crítica bem-sucedida mostraria, portanto, as ilegitimidades que sáo perceptíveis em cada formação social. Em última instância, mostrando a sensibilidade para determinados traços do mundo que estariam sendo conspurcados, a construção da crítica demonstra a lógica cultural que preside, que vertebra, a formação social estudada.

Operacionalmente, poderíamos dizer que a "operação crítica da crítica" seria "riscar o chão da sociedade", instituindo uma linha divisória entre os $1 \%$ mais ricos e o resto dos seus habitantes, mostrando que o jardim daquele lado é mais bonito e que essa beleza foi construída por todos, mas apropriada apenas pelos que conseguiram ficar do lado mais bonito da cerca. A jusante, se o enunciado ganha repercussão, poderíamos dizer que a operação crítica foi bem-sucedida. Conforme registrado por Pierre Bourdieu, a partir da filosofia de Goodman (1978), o essencial da luta política consiste justamente em manter ou alterar as linhas de percepção das divisóes do mundo social (BOURDIEU, 1997).

A não atenção social à possível demarcação dos " $1 \%$ " demonstra o insucesso da crítica. Seria esta última simplesmente mal formulada, no sentido de que outras tentativas, mais hábeis ou mais bem informadas, conseguiriam chamar a atenção da sociedade e sensibilizá-la? Haveria uma força maior do que as vontades e as habilidades impedindo a concretização da crítica? A resposta a essas questóes mostra a interdependência entre elas, no sentido de que uma interage com a outra. Tanto a boa-vontade para com a crítica quanto a habilidade e vontade dos críticos, nenhuma das duas emerge porque ambas estão submetidas a um processo de dominação cultural que é independente da qualidade intrínseca dos argumentos e mesmo da educação dos seus formuladores ou da sua audiência. Esse é 
um dos aspectos da dureza da realidade simbólica. Ela não é intuitiva, pois justamente fere o preceito fundamental do mundo acadêmico de que o bom argumento, a retórica e eloquência adequadas e a capacidade cognitiva do auditor seriam condiçóes necessárias e suficientes para estabelecer a necessidade de alguma ação social e a consequente ação política no sentido de concretizá-la.

\section{O “efeito Piketty” e a crítica esboçada da assimetria econômica}

Segundo a narrativa prevalecente nos meios acadêmicos, e mesmo corporativos, o chamado "efeito Piketty" (SALGADO, 2014) produziu a mudança de comportamento nos órgãos públicos brasileiros e dados sobre a concentração de renda e patrimônio passaram a circular e serem disponibilizados para a análise científica. Verdadeira ou falsa a afirmação da relevância intrínseca do livro de Thomas Piketty (2013, 2014a, 2014b), o fato é que ele deflagrou a necessidade, tanto no Brasil quanto internacionalmente, de ser contraditado pelos porta-vozes dos mercados financeiros e economistas que costumam coabitar esse espaço. Sofregamente, apareceram dezenas de refutaçóes mais ou menos inspiradas ${ }^{7}$.

Seria difícil encontrar na história dos debates econômicos uma obra que tenha suscitado tanta crítica, especificamente, tantas tentativas de refutação e tão rapidamente, denotando a sensibilização de seus adversários intelectuais e políticos. Em si mesmo, esse fato merece uma análise sociológica. É evidente que Piketty "machucou a doxa". Como e por que, nesse momento, é algo a ser esclarecido e uma excelente pauta tanto para a sociologia da finança quanto da ciência e dos intelectuais. De qualquer forma, fica a evidência de que as refutações, aqui também pouco importando realmente a qualidade intrínseca delas, acabam chamando ainda mais a atenção para o próprio problema da distribuição de riquezas na sociedade. Normalmente, no universo político dominado pela escandalizaçáo, esse efeito de saturaçáo é uma ocorrência que beneficia os quadros

\footnotetext{
Para saber mais, ver: WRIGHT e FRÉMEAUX (2014).

7 Fiquemos aqui com três representantes da imprensa e think tanks ligados às finanças, além da revista Exame: SALGADO (20I4); PIKETTY (20I4); SMITH (20I5); DUBAY; FURTH (20I4).
} 
argumentativos conservadores. Estamos aqui diante de um raro acontecimento em sentido contrário, o que aumenta a curiosidade científica da explicação do que poderíamos chamar de "momento Piketty".

Em uma primeira aproximaçáo, poderíamos dizer que os meios acadêmicos seriam justamente o setor da sociedade no qual o argumento "racional", ou "escolástico", da lógica do esclarecimento direto e sem vieses prosperaria com mais vigor. Entretanto, as lentes da cognição social impóem um limite ao esclarecimento científico e mesmo aos agentes sociais encarregados dessa tarefa.

Em relação ao nosso ponto específico, ficou convencionado que a repercussão, primeiro internacional, depois nacional, do best-seller de Thomas Piketty evidenciou a singularidade do caso brasileiro e teria induzido o governo federal petista, então no ocaso, a romper a inércia e liberar os dados num nível de agregação possível de ser mensurado e comparado internacionalmente, culminando com a publicação circunstanciada de dados mais de acordo com a expectativa dos nossos "empreendedores morais".

Mas será que a explicação "naturalística", ou "indígena", ainda que lógica racionalmente, pode satisfazer a sociologia do conhecimento, ou compor efetivamente com a sociologia política do Brasil contemporâneo? O Brasil viveu, desde o início da primeira década do século XXI, um intenso processo de polarização política entre contestadores e partidários dos governos petistas no qual, dado o estado da oferta internacional de artefatos para exprimir o desconforto com a desigualdade econômica que os governos petistas insinuavam combater, seria muito provável que emergisse o " $1 \%$ " como o condensado social dos inimigos da esquerda no poder que impediram o pleno desenvolvimento de seu programa de governo e acabaram conspirando e derrubando sua última Presidenta. Ou, num registro inverso na causalidade, mas convergente na esfera cultural, um enredo próximo das fabulaçóes associadas ao fascismo europeu, sustentando a interpretação contrária de que os governos petistas visavam fundamentalmente

8 Isso porque, posteriormente, no espaço disciplinar da Economia, a "anomalia" se corrige, conforme comentário informado em: a seguir: STEIBAUM (20I7). Ver também: HOSKINS e TULLOCH (20I6).

9 Ver: MINISTÉRIO DA FAZENDA (20I6). 
melhorar os rendimentos dos $1 \%$ ou os $0,1 \%$ mais ricos e disfarçavam seu intento de massacrar as classes médias distribuindo esmolas aos mais pobres, como o bolsa-família.

Mas não foi nem um nem outro. Num curto, mas extremamente denso lapso de tempo, tivemos uma cronologia significativa, começando com uma sequência de "plutocratas", essa subsérie culminando com Daniel Dantas e a deflagração do escândalo do mensaláo ${ }^{10}$. Entretanto, logo depois infletimos para as "elites brancas"11 e, em seguida, instalou-se duravelmente o "PiG" - Partido da imprensa Golpista" (GRÜN, 2014).

A intensificação da desigualdade e a polarização política são fenômenos internacionais, dificilmente poderiam ser considerados "jabuticabas". Mas a produção intelectual e genericamente cultural que dá conta delas é singularmente autóctone. E nosso problema sociológico será então como explicar essa assimetria entre a produção de crítica no Brasil e aquela percebida contemporaneamente no "I Mundo".

Como apontaram destacadamente Florestan Fernandes (1975) e Raymundo Faoro (1958), o Brasil pode ser considerado um caso de hipertrofia precoce do setor financeiro, um fenômeno que, na lógica "naturalista", deveria engendrar figuras da crítica análogas àquelas esperadas pela financeirização internacional contemporânea. Entretanto, fora dos episódios circunscritos do encilhamento (TAUNAY, 1923 [1893]; DINIZ, 1996) e do integralismo (MAIO, 1992), pouco ouvimos do assunto, pelo menos até o advento do processo de privatização das empresas estatais empreendido nos anos de 1990, durante os governos FHC.

Naquele momento começou a emergir uma crítica sistemática, localizando os plutocratas que seriam responsáveis pelo processo, considerado antinacional e antipopular. ${ }^{13}$ Afinal, décadas de capitalismo empurrado

10 Ver: ROMERO (2005) E SENADO NOTÍCIAS (2005).

II Ver: BERGAMO (2006).

12 Ver também: AMORIM (2006).

13 A Wikipedia lista um rol de especuladores financeiros muito próximos da escroqueria tradicional (e não da figura legitimada do financista contemporâneo), que ficaram famosos no período da ditadura militar, como o caso "Coroa-Brastel" (ver: ESCÂNDALO... [2018]) e a caderneta de poupança Delfim (ver: CASO DELFIN [2018]). Mas, aparentemente, seus feitos e fama ficaram restritos a segmentos específicos da população. 0 
pelo Estado, todo um sistema de regulação iniciado no período getulista, estariam sendo desfeitas com a amputaçáo do braço da indústria estatal, e essa mudança nas formas de convívio econômico e social muito provavelmente acabaria gerando uma onda de crítica. Nesse sentido, vemos que, efetivamente, a crítica recupera algumas figuras públicas dos especuladores financeiros e especificamente bursáteis, que irão produzir uma sequência cronológica interessante primeiro nela mesma, mas também pela sua súbita interrupção e substituição por outro tipo de figura, construída em outra lógica e dirigindo a crítica para outros aspectos da realidade. Ainda que não sejam os " $1 \%$ ", a lógica de representação dos plutocratas desenha a assimetria como um privilégio especificamente econômico, como riqueza material indevida e, normalmente, não só recém-adquirida, como também às custas de alguma manobra que expolia o público.

$\mathrm{Na}$ cena brasileira, a figura do plutocrata reaparece depois de décadas de hibernação justamente nos anos de 1990, período da privatização empreendida pelos governos peessedebistas (GRÜN, 2008). Na cena internacional, vimos claramente a emergência do "megaespeculador" Georges Soros e, em seguida, nosso "coletivo dos 1\%" (GUILHOT, 2006. KEISTER, 2014). Podemos entáo propor e esperar que a emergência pública dessa primeira figura costume anteceder cronologicamente a criação da figura pública dos "1\%". Mas, no Brasil, a cronologia esperada se interrompe nos governos petistas, ainda que no início dessa experiência Daniel Dantas, principal acionista do Banco Opportunity, tenha apresentado uma presença mais do que destacada ${ }^{14}$ (GRÜN, 2008).

\section{A emergência do especulador}

Os altos e baixos do mercado de açóes entre os anos de 1970 e 1980 nos trouxeram as versóes nacionais do "megaespeculador", dos quais o paulista de origem libanesa Naji Nahas acabou se tornando o exemplo

caso Banestado (ver: O ESCÂNDALO DO BANESTADO [2018]) talvez tenha sido o mais rumoroso do periodo que antecedeu o aparecimento do "plutocrata" Daniel Dantas. Ele parece assinalar o início de uma elaboração coletiva do problema da plutocracia.

14 Ver: LÍRIO (2005). 
mais expressivo ${ }^{15}$. Mas o mundo do mercado de açóes ainda era mais ou menos apartado do resto da sociedade, da chamada "economia real", sendo considerado uma espécie de cassino no qual cada um entra por conta e risco e náo pode se lamentar nem despertar a piedade da sociedade para com sua má sorte (GRÜN, 2004; MAGLIANO FILHO, 2014).

A redemocratização também soprou no mundo das finanças e, principalmente, por meio dos fundos de pensão e dos fundos de investimentos em renda variável. Parcelas muito amplas da população passaram a depender e a acompanhar o mercado financeiro, especialmente a Bolsa de Valores. O debate se intensificou e tomou um rumo mais ou menos esperado com o advento das privatizaçóes, quando diversas personas foram caracterizadas por grupos de críticos como a encarnação do personagem "plutocrata". Mas o evento subsequente da eleição de Lula para a Presidência da República e a crítica a essa "anomalia" alteraram a configuração da cosmologia brasileira contemporânea, aparecendo, de um lado, os "ladrôes do PT", aos quais se imputou o "mensaláo" e, depois, o "petróláo"; e, no extremo oposto, mas em equilíbrio simbólico, o chamado "Partido da imprensa Golpista”, o PiG, a figura que passou a condensar a propalada conspiração das elites tradicionais contra o advento do governo a favor das demandas populares (GRÜN, 2006).

Além disso, a microcronologia dos meses de 2002, ano da primeira vitória de Lula nas eleições presidenciais, mostraram-nos a famosa "Carta aos Brasileiros" e também a menos evidenciada, mas talvez até mais importante, visita de Lula à Bovespa no imediato antes da sua eleição. Em um momento subsequente, já no exercício da presidência, os brasileiros escutaram declaraçóes de Lula a favor dos fundos de pensão, mencionando a "sagrada poupança do trabalhador". De maneira deplorável para muitos críticos que assinalavam a cumplicidade entre o governo Lula e o mercado financeiro, ${ }^{16}$ observamos então uma convergência no sentido de construir um espaço de equivalências, uma validação mútua entre a legitimidade política do governo e a credibilidade econômica dos mercados financeiros (GRÜN, 2005, 2009).

15 Ver: O GLOBO (2008) E KROEHN (2016).

16 Para saber mais, ver: BIANCHI e BRAGA (2011). 


\section{O ponto crítico da sociologia da crítica}

Para nossa proposta de sociologia dos intelectuais, o decisivo é que passamos de uma figura que organizava o debate em torno das assimetrias diretamente econômicas para outra em que a distribuição desigual de recursos culturais era a assimetria mais característica. Ao invés do "Money talks" da cena internacional, nos acostumamos com uma narrativa sobre o bloqueio da publicidade das razóes dos partidários do governo popular por parte dos donos da mídia e de seus prepostos diretos e indiretos nos jornais e demais meios de comunicação. Por que o Brasil contemporâneo seguiu esse caminho particular, aparentemente fruto da nossa "jabuticaba"?

Minha hipótese é de que a disputa política entre os dois grandes partidos no Brasil contemporâneo, que foi estruturada no processo de redemocratização política dos anos de 1980, segue uma lógica cultural, advinda da sua origem no espaço da cultura e, especificamente, acadêmico. Essa lógica fez implantar um sistema simbólico baseado no par "alto clero/baixo clero", tendo como princípio mnemônico a imposição da "lição de casa" aos assujeitados (GRÜN, 2016). Essa particularidade ocorre porque o sistema simbólico tem suas origens em uma disputa sobre os rumos das universidades nesse imediato pós-redemocratização e essa origem acadêmica acabou revestindo sua retórica e espraiou sua pegada para outros espaços sociais.

Histórica e comparativamente, a literatura sugere que se trata de uma característica típica de jovens democracias, nas quais ainda não se consolidou uma esfera própria e autorreproduzida da ação política, ou quando alguma alteração dramática causada por interrupção do processo democrático ou extensão dos contingentes de eleitores desaloja a antiga elite local (EYAL; BUCHOLZ, 2010). Nessas situaçóes, a mercê de seu capital simbólico, intelectuais e acadêmicos (mas também celebridades de outras origens e capitais, do religioso ao show business, passando pelo esporte) podem ocupar espaços desproporcionais no âmbito da representação política até que esse espaço "se emancipe", criando suas próprias leis de reprodução social. Uma vez tal "estágio" alcançado, a janela entre os dois mundos tende a se fechar ou se estreitar e "a anomalia se corrige", no sentido de diminuírem as chances de celebridades em outros espaços serem reconhecidas como atores políticos plenos. 
Escusas e possibilidades laterais apontadas, permanece a necessidade de dar conta da origem e das consequências dessa estrutura do debate e da crítica social e cultural imperantes no Brasil contemporâneo. O sistema simbólico surge como a afirmação da primazia do grupo de intelectuais dos quais FHC foi um dos participantes mais importantes, inicialmente no âmbito da Universidade de São Paulo (USP) e, em seguida, como efeito colateral da catapultada de Cardoso no espaço nacional, para diversas outras esferas.

O sistema simbólico ordena o mundo universitário no imediato pósditadura militar, conferindo a esse grupo, que se queria portador de uma renovação e internacionalização do espaço, o lugar de "alto clero", atribuindo a seus adversários na busca de contemporaneidade, esses últimos mais ligados ao nascente sindicalismo universitário, o epíteto menos brilhante de "baixo clero" (GIANNOTTI, 1986). Com o tempo, corporificou-se uma forma típica de imposição dessa hierarquia por meio de um interessante enxerto à fórmula: o estabelecimento, e aceitação, da "lição de casa" qual seja, a versão especificamente nacional do assujeitamento cultural, por meio do reconhecimento da capacidade de diagnóstico e prescrição do primeiro grupo na construção e interpretação da realidade e dos meios para corrigir suas imperfeiçóes (GRÜN, 2013, 2016).

O poder simbólico adquirido nessa instituição categorial, provavelmente inédito, vai acompanhar o grupo e, mesmo, se reforçar nos anos e disputas seguintes, especialmente nos oito anos de mandato presidencial de Cardoso. Este, conhecido como nada menos do que o "Príncipe dos sociólogos", ${ }^{17}$ não só se tornou a encarnação mesma do alto clero como também conquistou o direito de arbitrar a vida ou a morte simbólica no espaço cultural e político brasileiro da época, por meio do poder de ostracismo: a atribuição da condição de "dinossauro" para qualquer indivíduo ou grupo que se interpusesse no seu caminho e a "condução coercitiva" dos indigitados para o "Parque Jurássico". ${ }^{18}$

Um dos pontos mais interessantes da configuração simbólica que se corporificou no período é, justamente, a sua resiliência. $\mathrm{O}$ chamado "poder

17 Para saber mais, ver: COSTA (2016).

18 Para saber mais, ver: TAVARES (1997). 
regaliano" (BOURDIEU, 1980) de dividir o mundo entre "modernos" e "ultrapassados", esses últimos condenados inapelavelmente ao ostracismo do "Parque Jurássico", não abandonou o grupo mesmo depois da derrota eleitoral em 2002. A tutela sobre a política econômica do novo grupo no poder talvez tenha sido a maior manifestação desse poder simbólico (GRÜN, 2015 , 2016). Além das perguntas mais gerais que esse predomínio deve colocar à sociologia, é aqui pertinente investigar se e como o sistema simbólico que corporificou a verdadeira hegemonia do grupo se enraizou na cultura do País para, em seguida, verificar as possibilidades utilizadas para ultrapassá-lo, as dependências de caminho que essa forma particular de contenda deixou no campo do poder do Brasil contemporâneo e, especificamente, os resultados pouco perceptíveis das tentativas de ultrapassagem.

\section{As consequências práticas da instalação do novo sistema simbólico}

Esse padrão de dominação induz enquadramentos da realidade que produzem um tipo de invisibilidade e um caminho claro para a transformação de capital cultural em capital econômico. Primeiro, a versão brasileira do chamado "racismo da inteligência": a justificação e mesmo a naturalização das assimetrias produzidas pela distribuição desigual de capital cultural (BOURDIEU, 2004). Segundo, um padrão de crítica específico para essa assimetria - a denúncia da meritocracia escolar tradicional, indicador e produtor mais visível dessa saliência, como um processo enviesado a favor dos membros das famílias privilegiadas. Começa aí a aparecer um resultado inesperado e outro esperado: primeiro, conforme o esperado, o enquadramento cultural das gestóes governamentais petistas batendo contra o muro da dominação social dos seus adversários. Nesse sentido, o desfecho do impedimento de Dilma é uma espécie de "prova do pudim", pois mostra que esses governos foram caracterizados como principalmente corruptos, desfazendo os méritos possíveis e interpretaçóes alternativas dos seus atos políticos. Mas a dinâmica do período se restaura ao constatarmos o sucesso, pelo menos parcial, da denúncia sobre as assimetrias culturais durante o período petista, suscitando uma revisão do critério prevalecente de mérito escolar em várias arenas importantes por meio da instauração do sistema de cotas raciais e sociais. 
O enquadramento "governos corruptos" não surge por acaso. $\mathrm{Na}$ verdade, ele é uma expressão precisa da doxa social que rege a sociedade brasileira contemporânea. A relativização da ideia prevalecente de meritocracia sinaliza uma mudança significativa no futuro, sendo muito relevante acompanhar a forma como os governos saídos do impedimento de Dilma lidam com essa questão que deve incomodar parte das suas bases de apoio. ${ }^{19} \mathrm{O}$ novo entendimento foi pacificado por uma sentença colegiada do Supremo Tribunal Federal e é inegavelmente popular, sugerindo um interessante decoupling entre a sociedade em geral e suas elites, conforme apontam pesquisas de opinião realizadas por instituiçóes diferentes em momentos diversos e, ponto extremamente interessante para uma sociologia da crítica, sem gerarem repercussão significativa na esfera da opinião pública ou, especificamente, no debate político partidário ${ }^{20}$.

Sobre os "governos corruptos", podemos analisar mais circunstanciadamente já em 2017. Nossa doxa é, parafraseando Nelson Rodrigues, de um óbvio tão ululante que nos ofusca e oblitera sua ação. É interessante aqui tentar esclarecer esse ofuscamento ensaiando uma explicação por meio do par "regras morais/regras técnicas" que atravessa a obra de Durkheim (MÜLLER, 2013). As primeiras dizem respeito aos fatores de coesão mais gerais da sociedade, compartilhados pela cultura nacional e mormente consagrada no aparato legal. As regras técnicas dizem respeito à maneira circunstanciada de alcançar tais objetivos. Boltanski (2009) aplica essa distinção propondo uma teoria da dominação mais geral e especifica essa análise para explicar a teoria da estratificação social que está implícita nos romances policiais ingleses e franceses do final do século XIX e primeira metade do século XX e se tornou básica para a construção de narrativas fabulares sobre a estrutura social do capitalismo (BOLTANSKI, 2012).

Os diversos agentes encarregados de cumprir ou fazer cumprir as funçóes do Estado ou, mais genericamente, da sociedade, devem, normalmente, realizar essas tarefas a partir das regras técnicas assinaladas. Mas há exceções importantes. E são elas que realmente corporificam, dão concretude à regra. Quando uma regra técnica impede a consecução de uma regra

19 Para saber mais, ver: MENDONÇA (2017).

20 Para saber mais, ver: TOLEDO (20/3). 
moral, a primeira deve ser contornada. Entretanto, como a interpretação dessa divergência é intrinsecamente controversa, existe a necessidade de se aferir tanto a discrepância quanto a qualidade da solução aventada (BOLTANSKI, 2012).

Assistimos, no Brasil contemporâneo, a uma especificação dessa sutileza. E, para dar conta dela, propomos uma aproximação com a sociologia crítica de Bourdieu: quem, quando e como pode aferir primeiro a excepcionalidade de um evento e, em seguida, arbitrar a justeza de procedimentos e pureza de intençóes dos decisores quando ocorrem aqueles eventos catalogados como excepcionais? Olhando a jusante, vemos como a hierarquia de fundo cultural que se desenvolveu no Brasil contemporâneo impóe uma solução. E, sub-repticiamente, se instala a ordem social para, e principalmente, por meio dessas situaçóes, as quais, se pensadas exclusivamente pelo seu lado semântico, poderiam ser consideradas indeterminadas.

\section{A dureza da realidade simbólica se esconde atrás da sua aparente flexibilidade}

A observação do jogo social nessa época de polarização permite verificar com maior clareza como a sociedade escolhe árbitros para "desambiguizar” as contendas, e não os escolhe por acaso. E a partir daí podemos entender melhor como funciona nossa ordem simbólica e também, por dedução, vislumbramos os limites da polarização. A metáfora física "polarização" sugere uma relação de forças simétrica, mas na verdade apenas um dos lados "tem a força". Na relação de forças simbólica, um grupo joga "downhill", usando a "força da doxa", as habitualidades cognitivas, frutos da incorporação da história nos indivíduos, que funciona como uma força da gravidade social e cultural a seu favor e também conta com a boa vontade da arbitragem. Enquanto isso, os atos e as tentativas de conformar fatos a partir do outro lado do nosso tabuleiro social estáo marcados, originalmente, por desconfiança e descrença, tendo a história e as habitualidades contra essas possibilidades, as quais, aqui, precisam necessariamente serem denominadas contraintuitivas.

Grosso modo, os petistas e os intelectuais que sustentam sua experiência no governo federal pretendem ter realizado um portfolio importante 
de realizaçôes na área social e mesmo econômica, tendo o problema social como deflagrador das soluçôes econômicas. Um círculo virtuoso se produziria a partir do aumento da renda das classes normalmente desfavorecidas, que induziria ao consumo, ao aumento da produção, ao investimento em ampliação das capacidades produtivas e à retroalimentação dessa sequência. Na versão que propóem, os eventuais deslizes na sua prática política deveriam ser debitados à necessidade de contornar as dificuldades inerentes do sistema político brasileiro para a consecução de suas nobres intençôes. No papel, mas apenas nele, poderíamos apontar essa situação como um exemplo de flexão de regras técnicas para realizar uma regra moral.

Seus adversários negam tais feitos, não necessariamente neles mesmos, mas nas intençóes que estariam por trás de tais iniciativas. Estaríamos diante de manobras para encobrir as intençóes de enriquecimento ilícito dos agentes políticos dessa experiência e da sua perpetuação no poder por meio da fidelização das parcelas mais destituídas da população e do eleitorado. A maior parte da sociedade brasileira, especialmente do seu sistema jurídico, nega terminantemente a versão petista, o que se consubstancia pela cruzada condenatória que os membros dessa corrente foram objeto desde o julgamento do "mensaláo".

Os petistas não seriam capazes de impor uma regra moral na sociedade ou, pelo menos de se fazerem respeitar como intérpretes autorizados para dirimir dúvidas em situações ambíguas. Assimetricamente, seus adversários principais teriam essa virtualidade a seu favor, e atos aparentemente idênticos perpetrados por uns e outros ganham pesos inversos na sociedade, para desespero dos petistas e gáudio dos seus adversários. Cruamente, o enunciado se realiza na constatação de que a sociedade não aceita uma possível razão superior que justifique os procedimentos dos governos federais do Partido dos Trabalhadores (PT). Pretendiam justificar seus atos como a tentativa de conseguir a maioria parlamentar para seus presidentes da República, condição necessária para a realização de seu programa de governo dito progressista. Tal desiderato foi considerado uma mera prestidigitação: chamar a atenção da sociedade para uma ação com finalidade justificável; quando o essencial da atividade era a realização de uma finalidade espúria no nível político, a tentativa de se manter no poder indefinidamente, e 
nefanda no nível pessoal de seus dirigentes, o enriquecimento ilícito. Em suma, sua magia foi desconstruída, considerada "de araque".

Estamos diante de um "jogo" social no qual a possível polissemia de uma linha de ação e de justificação é flexionada decididamente no sentido contrário ao desejado pelos atores identificados com o petismo. Esse resultado confirma a dominação cultural que seus adversários mantêm sobre a sociedade brasileira. O alto clero diz qual é a direção certa e arbitra quais movimentos efetivamente são válidos para encaminhar a sociedade nesse sentido.

\section{Sistema classificatório e dominação social}

A dinâmica das ousadias e submissões da política econômica petista e, mais especificamente, dos escândalos que sacudiram aqueles governos, mostraram o baixo grau de liberdade que os atores respectivos puderam dispor no período em que estiveram no governo federal. Importa-nos aqui discutir por onde transcorreram as estratégias políticas para lidar com essas contrariedades, que o erudito chamaria de enfrentamento da dominaçáo simbólica. A hipótese situada para o artigo é que explicam as razóes da “jabuticaba cultural” brasileira.

A expansão do sistema universitário e a política de cotas para os segmentos desfavorecidos ocorridas durante o período petista podem ter tido qualquer gênese específica. Por exemplo, podem ter surgido de uma sugestão do marketing político engendrada por pesquisas mercadológicas sobre o levantamento de demandas populares a serem pesadas e escolhidas como prioridade. Podem estar ancorados em políticas e movimentos anteriores à ascensão dos petistas. Podem ser, estatisticamente, menos relevantes do que a propaganda tenta fazer crer. Podem ser mal concebidos ou mal administrados. Mas, na dinâmica dos escândalos, esses dois eixos se tornaram referências identitárias para os petistas e para todos os que se identificaram com essa tendência, vencedora de quatro eleiçóes presidenciais seguidas desde 2002, não nos esqueçamos.

Os "coxinhas" (a denominação pejorativa que prevalece no período para os adversários dos governos petistas, à qual se opóem os "mortadelas", o equivalente para desqualificar os petistas, provavelmente por ser um alimento considerado popular) estariam tentando inebriar o povo com 
o tema da corrupção para desviar a atenção dos progressos sociais do período e mesmo revertê-las. Para ter sucesso nessa prestidigitação, seria necessário manter o povo em estado de ignorância, além dessa ignorância também agradar a clientela tradicional da "direita", que se revoltou contra programas governamentais de grande envergadura, como o dos "médicos cubanos" ${ }^{21}$. Nesse contexto de acirramento de tensôes, a política educacional petista termina sendo caracterizada por seus adeptos como tendo o horizonte de "romper com esse domínio da ignorância", imposto pelas elites tradicionais.

A narrativa apresentada pode ou não encontrar guarida nas ações ou intençôes dos adversários dos petistas. Mas certamente é resultado e retroalimenta a sensibilidade para o eixo da assimetria cultural. E talvez a maior comprovação a jusante dessa inscrição é verificarmos que as diversas rodadas de confronto cultural apensaram a essa rubrica inclusive programas menos típicos, como o "Ciência sem fronteiras". E no ambiente politicamente polarizado dos governos petistas instalou-se a agenda da assimetria de recursos culturais, os petistas querendo diminuí-las e os seus adversários querendo mantê-las intactas, ou mesmo aumentá-las.

A oposição a esse enquadramento da realidade passa fundamentalmente por um questionamento das prioridades educacionais dos governos petistas. Aparece, se estrutura e também "ganha realidade" a versão concorrente de que a melhor alocação de recursos na educação seria investir prioritariamente na "base da pirâmide", nos graus inferiores do ciclo educacional, para só depois, quando o país dispuser efetivamente de um universo de alunos de segundo grau realmente bem preparados, passar a investir maciçamente no ensino superior.

Notemos que, nela mesma, em termos da sua lógica interna, a versão adversária também é defensável. Mas é atacada por manter estática a distribuiçáo de capital cultural no seio das elites e grupos que tentam adentrar nesse campo do poder. Cruamente, na linguagem que se formou para expressar os dilemas do Brasil contemporâneo, por querer "preservar a elite branca no poder", argumento que encontra guarida no decoupling

21 Para saber mais, ver: MIDIA LIVRE (20/3). 
dos resultados das pesquisas de opinião sobre cotas acima referenciadas. Assim caracterizada, ela se configura como um argumento para a preservação dos privilégios das elites já instaladas. Ela teria então uma falsa intenção denunciatória, pois tenta fazer passar como interesse da sociedade em geral uma proposta mesquinha, que fundamentalmente serve para preservar os interesses de um grupo já privilegiado (BOLTANSKI; DARRÉ; SCHILTZ, 1984; BOLTANSKI, 1993).

Mais uma vez, na tentativa de desambiguizar a disputa, estamos diante de uma relação entre regra moral, regra técnica e o direito de dizer qual é a regra moral que deve preponderar e quem a está cumprindo com maior fidelidade. E, nesse caso, as razóes do nosso alto clero não parecem preponderar. Pelo menos nas primeiras rodadas.

Estamos aqui na encruzilhada entre dois princípios de construção de regras morais, aquele que diz ser obrigação do governo do país, como pai do povo, educar seus filhos da melhor maneira possível e a outra regra "de ouro", que manda não gastar mais do que se ganha. Válidas nelas mesmas, as duas regras dificilmente podem ser combinadas, pelo menos sincronicamente. Diacronicamente, "se apertarmos o cinto no momento certo, poderemos desapertá-lo quando a crise estiver superada” ou, alternativamente: "se não fizermos os investimentos sociais agora, teremos uma ou mais geraçôes de brasileiros perdidas nas esferas do trabalho, educação e saúde". Mais uma vez, observa-se a simetria na qualidade intrínseca dos argumentos. Como seria possível "desempatar esse jogo"?

\section{À guisa de conclusão: o “campo dos escândalos”, operador prático da dominação cultural}

A história responde: períodos pessimistas favorecem a extensão metafórica do princípio rigorista, da necessidade de apertar os cintos (LAKOFF, 1996; MUEL-DREYFUS, 1996). A lógica do campo dos escândalos, que começou a se produzir no Brasil contemporâneo com a extensão da democratizaçáo e que se consolidou no governo federal petista, produz o pano de fundo da narrativa do futuro como a catástrofe que se avizinha, que alimenta e retroalimenta continuamente o pessimismo estrutural (GRÜN, 2018). 
A escandalização bem-sucedida reitera a doxa nas diversas esferas da decisão social estigmatizando as ousadias. Ela encontra combustível para isso em quaisquer dificuldades que poderiam ser apontadas como fracassos ou imperfeiçóes das razóes e medidas governamentais que atentavam contra esse senso comum conservador. Injusto, diriam os petistas, mas lógico, se pensarmos que a inércia está do lado contrário ao deles.

Não é, assim, por acaso, que no transcurso dos governos petistas a corda foi progressivamente apertando os pescoços daqueles que desobedeciam ao princípio do rigor e da necessidade de purgação para expiar os pecados da transgressão da doxa. Dessa história social e cultural do presente, importa aqui ressaltar que também não é por acaso que a principal figura da crítica se oriente para a esfera cultural. O constrangimento de ordem simbólica, a obliteração das razóes dos governos e apoiadores do PT aparece na esfera pública e também na subjetividade dos agentes envolvidos com a política, ao mesmo tempo como o mais flagrante impedimento à consecução dos programas pensados e instituídos pelos governos petistas, como também mais fácil de flanquear do que uma batalha aberta sobre a condução da economia do País.

E o caminho histórico aqui apontado oblitera a possível, mas até agora inexistente, ereção dos "1\%" como figura social de crítica e, em geral, da assimetria de recursos econômicos como base da contestação ao status quo brasileiro. As estatísticas apontam o Brasil como o caso mais extremo de desigualdade, os estudos mais recentes da equipe de Thomas Piketty confirmam - e mesmo ampliam - essa afirmação, mas ela não ganha foro de crítica social $^{22}$. Por maiores que sejam os esforços exclusivamente intelectuais, eles não conseguem "riscar o chão" da sociedade brasileira e instituir a percepção da "gravidade" da assimetria de renda e de riqueza.

Entretanto, o Brasil recente alterou significativamente a noção de meritocracia para compor com as assimetrias de origem étnica ou social. O sucesso eleitoral dos governos que empunharam essa bandeira assinalou o "risco do chão" que se percebe na sociedade brasileira. Ouso concluir que tal peculiaridade compóe e decorre justamente do sistema simbólico

22 Ver, por exemplo: ODILLA, PASSARINHO e BARRUCHO (2018); BORGES (2017) e DONCEL (2018). 
alto-baixo clero/lição de casa, já que ele nos educa a prestar atenção nas desigualdades de condições de acumulação de capital cultural. Os esforços na esfera política dos prejudicados na hierarquia cultural acabam criando um caminho, uma rota a partir da qual as outras desigualdades podem se encaixar, mas como decorrências da primeira.

\section{Referências}

ALMEIDA, A. M. F. O assalto à educação pelos economistas. Tempo Social, v. 20, n. 1, p. $163-178,2008$.

AMORIM, Paulo Henrique. Como governar quando toda a imprensa é contra. 2006. Disponível em: <http://misturadigital.blogspot.com/2006/10/como-governar-quando-toda-imprensa.html>. Acesso em: 16 set. 2018.

BALIBAR, Étianne et al. L' injustice sociale, quelles voies pour la critique? In: BOLTANSKI, L. Inégalités et classes sociales. Quelles entités pour quelles sociologies? Paris: Presses Universitaires de France, 2013. p. 79-102.

BERGAMO, Mônica. Burguesia terá de abrir a bolsa, diz Lembo. Folha de S. Paulo, São Paulo. 15 maio 2006. Disponível em: <https://www1.folha.uol.com.br/folha/cotidiano/ult95u121683. shtml>. Acesso em: 16 set. 2018.

BIRNBAUM, P. Le peuple et les gros: histoire d'un mythe. Paris: Hachette Pluriel Reference, 1979.

BOLTANSKI, L. La souffrance à distance: morale humanitaire, médias et politique. Paris: Métailié, 1993.

De la critique: précis de sociologie de l'émancipation. Paris: Gallimard, 2009.

Énigmes et complots: une enquête à propos d`enquêtes. Paris: Gallimard, 2012.

BOLTANSKI, L.; CLAVERIE, E.; OFFENSTADT, N. Affaires, scandales et grandes causes de Socrate à Pinochet. Paris: Stock, 2007.

BOLTANSKI, L.; DARRÉ, Y.; SCHILTZ, M.-A. La dénonciation. Actes de la Recherche en Sciences Sociales, Paris, v. 51, p. 3-40, 1984.

BORGES, Rodolfo. Brasil tem maior concentração de renda do mundo entre o $1 . \%$ mais rico. El País, Madri, 14 dez. 2017. Disponível em: <https://brasil.elpais.com/brasil/2017/12/13/ internacional/1513193348_895757.html>. Acesso em: 16 set. 2018.

BOURDIEU, P. Le sens pratique. Paris: Editions de Minuit, 1980.

L'identité et la représentation [Éléments pour une réflexion critique sur l'idée de région].

Actes de la Recherche en Sciences Sociales, Paris, v. 35, p. 63-72, 1980. 
Méditations pascaliennes. Paris: Seuil, 1997.

2004

La précarité pour tous: racisme de l'intelligence. Le Monde diplomatique, França, abr.

Sociologie générale. v. 2. Cours au Collège de France, 1983-1986, édition établie par Patrick Champagne et Julien Duval avec la collaboration de Franck Poupeau et Marie-Christine Rivière. Paris: Raisons d'agir-Seuil, 2016.

BOUVERESSE, J.; ROSAT, J. J. Essais I. Wittgenstein, la modernité, le progrès et le déclin textes rassemblés par Jean-Jacques Rosat. Marseille; Montréal (Québec): Agone Comeau et Nadeau, 2000.

BRAGA, Ruy; BIANCHI, lvaro. A financeirizaçáo da burocracia sindical no Brasil. 2011. Disponível em: <http://csunidadeclassista.blogspot.com.br/2011/05/>. Acesso em: 16 set. 2018.

CASO DELFIN. [2018]. Disponível em: <https://pt.wikipedia.org/wiki/Caso_Delfin>. Acesso em: 16 set. 2018.

CHAMPAGNE, P. La manifestation. La production de l'événement politique. Actes de la Recherche en Sciences Sociales, Paris, v. 52-53, p. 19-41, 1984.

COLLINS, R. Interaction ritual chains. Princeton: Princeton University Press, 2004.

COLLUCCI, cláudia. 65\% apóiam cotas raciais na faculdade. Folha de S. Paulo, São Paulo, 23 jul. 2006. Disponível em: <http://www1.folha.uol.com.br/folha/educacao/ult305u18820.shtml>. Acesso em: 16 set. 2018.

COROA BRASTEL. [2018]. Disponível em: <https://pt.wikipedia.org/wiki/Esc\%C3\%A2ndalo_ Coroa_Brastel>.Acesso em: 16 set. 2018.

COSTA. Florência. FHC superstar. Isto é, São Paulo. 21 jan. 2016. Disponível em: <http://www. istoe.com.br/reportagens/42921_FHC+SUPERSTAR>. Acesso em: 16 set. 2018.

DATAFOLHA. Avaliaçáo da presidente Dilma Rousseff PO813824 25 e 26 de nov. de 2015. 2015. Disponível em: <http://media.folha.uol.com.br/datafolha/2015/11/30/avaliacao_dilma. pdf>. Acesso em: 16 set. 2018.

DAMPIERRE, E. D. Thèmes pour l'étude du scandale. Annales, v. 9, n. 3, p. 328-336, 1954.

DE BLIC, D. e. LEMIEUX, C. Le scandale comme épreuve: éléments de sociologie pragmatique. Politix, v. 71, n.3, p. 9-38, 2005.

DESROSIÈRES, A. Comment faire des choses qui tiennent: histoire sociale et statistique. Histoire \& Mesure, v. IV, n. 3-4, p. 225-242, 1989.

DINIZ, A. F. As representaçóes do encilhamento. 1996. Dissertação (Mestrado em História Econômica) - Universidade de São Paulo. USP, São Paulo, 1996.

DONCEL, Luis. Os problemas que se escondem por trás do pleno emprego nos países ricos. El país, Madri, 4 set. 2018. Disponível em: <https://brasil.elpais.com/tag/desigualdad_economica/ a>. Acesso em: 16 set. 2018 . 
DOUGLAS, M. Risk and blame: essays in cultural theory. London; New York: Routledge, 1992.

DUBAY, Curtis; FURTH, Salim. Understanding Thomas Piketty and His Critics. 2014. Disponível em: <http://www.heritage.org/research/reports/2014/09/understanding-thomaspiketty-and-his-critics>. Acesso em: 16 set. 2018.

ESCANDALO DO BANESTADO. [2018]. Disponível em: <https://pt.wikipedia.org/wiki/ Esc\%C3\%A2ndalo_do_Banestado>. Acesso em: 16 set. 2018.

EYAL, G.; BUCHHOLZ, L. From the Sociology of Intellectuals to the Sociology of Interventions. Annual Review of Sociology, v. 36, p. 117-137, 2010.

FAORO, R. Os donos do poder. Porto Alegre: Editora Globo, 1958.

FERNANDES, F. A revoluçáo burguesa no Brasil: ensaio de interpretação sociológica. Rio de Janeiro: Zahar Editores, 1975.

GIANNOTTI, J. A. Universidade em ritmo de barbárie. São Paulo: Editora Brasiliense, 1986.

GOBETTI, Sérgio Wulff; ORAIR, Rodrigo Octávio. Progressividade tributária: a agenda negligenciada. Texto para discussão 2190. 2016. Disponível em: <http://www.ipea.gov.br/portal/ images/stories/PDFs/TDs/td_2190.pdf>. Acesso em: 16 set. 2018.

GOODMAN, N. Ways of worldmaking. Indianapolis: Hackett Pub. Co., 1978.

GRÜN, R. A revolucao dos gerentes brasileiros. São Carlos: EdUFSCar, 1995.

Atores e ações na construção da governança corporativa brasileira. Revista Brasileira de Ciências Sociais, São Paulo, v. 18, n. 52, p. 139-161, 2003.

. A evolução recente do espaço financeiro no Brasil e alguns reflexos na cena política. Dados, Rio de Janeiros, v. 47, n. 1, p. 5-47, 2004.

Convergência das elites e inovaçóes financeiras: a governança corporativa no Brasil. Revista Brasileira de Ciências Sociais, São Paulo, v. 20, n. 58, p. 67-90, 2005.

Escândalos, marolas e finanças: para uma sociologia da transformação do ambiente econômico. Dados, Rio de Janeiro, v. 51, n. 2, p. 313-352, 2008.

Financeirização de esquerda? Frutos inesperados no Brasil do século XXI. Tempo Social, São Paulo, v. 21, n. 2, p. 153-184, 2009.

Escândalos, tsunamis e marolas: apontamentos e desapontamentos sobre um traço recorrente da atualidade. Revista Brasileira de Ciências Sociais, São Paulo,v. 26, n. 77, p. 151$174,2011$.

A vingança do baixo clero: o desafio ao "PiG" e o estado do conflito cultural no tratamento da crise financeira. Mana, [S.1.], v. 19, n. 2, p. 303-340, 2013.

Entre o PiG e o Mensalão: mitologia política e realidade contemporânea. Revista Brasileira de Ciências Sociais, São Paulo, v. 29, n. 86, p. 57-78, 2014. 
. Decifra-me ou te devoro: o Brasil e a dominação financeira. São Paulo: Alameda Editorial, 2015.

Capital cultural, conhecimento e dominação social: as pistas e os problemas levantados pela dominação financeira contemporânea. Sociedade e Estado, Brasília (DF), v. 31, n. 2, p. $403-$ 431, 2016.

Da pizza ao Tsunami: uma sociologia dos escândalos no Brasil, contemporâneo. São Paulo: Alameda Editorial, 2018.

GUILHOT, N. Financiers, philanthropes: sociologie de Wall Street. Paris: Raisons d'agir, 2006.

GUSFIELD, J. R. Symbolic crusade: status politics and the American temperance movement. Urbana: University of Illinois Press, 1986.

HACKING, I. Representing and intervening: introductory topics in the philosophy of natural science. Cambridge; New York: Cambridge University Press, 1983.

. Making up people. In: HELlER, T. C., SOSNA, M. e WELlBERY, D. E. (Ed.). Reconstructing individualism: autonomy, individuality, and the self in Western thought. Stanford: Stanford University Press, 1986. p. 222-236.

HOSKINS, A.; TULLOCH, J. Risk and hyperconnectivity: media and memories of neoliberalism. Oxford; New York: Oxford University Press, 2016.

ISTO É DINHEIRO. A volta do cassino na bolsa. 2016. Disponível em: <https://www.istoedinheiro. com.br/noticias/artigo/20160318/volta-cassino-bolsa/352416>. Acesso em: 16 set. 2018.

KEISTER, L. A. The One Percent. Annual Review of Sociology, v. 40, p. 347-367, 2014.

KILLEWALD, A.; PFEFFER, F. A.; SCHACHNER, J. N. Wealth Inequality and Accumulation. Annual Review of Sociology, [S.1.], v. 43, p. 379-404, 2017.

LAKOFF, G. Moral politics: what conservatives know that liberals don't. Chicago: The University of Chicago Press, 1996.

LAKOFF, G.; JOHNSON, M. Philosophy in the flesh: the embodied mind and its challenge to Western thought. New York: Basic Books, 1999.

LANGONI, C. G. Distribuiçáo da renda e desenvolvimento econômico do Brasil. Rio de Janeiro: Editora Expressão e Cultura, 1973.

LATINOBAROMETRO. Portal virtual. [2018]. Disponível em: <http://www.latinobarometro. org/latContents.jsp>. Acesso em: 16 set. 2018.

LEITE LOPES, J. S. Sobre o debate da distribuição da renda: leitura crítica de um artigo de Fishlow. Revista de Administraçáo de Empresas, São Paulo, v. 13, n. 3, p. 47-61, 1973.

LÍRIO, Sergio. O orelhudo tá nessa: as conexões entre Daniel Dantas, Marcos Valério, integrantes do PT e o depoimento da secretária., Carta Capital, XI, São Paulo, 29 jun. 2005. 
MACHADO, Juliana; ROCHA, Rodrigo. Reforma do Novo Mercado enfrenta resistência sobre divulgação de salário. Valor Econômico, São Paulo, 13 out. 2016. Disponível em: <https://www. valor.com.br/financas/4742317/reforma-do-novo-mercado-enfrenta-resistencia-sobre-divulgacaode-salario>. Acesso em: 16 set. 2018.

MAGLIANO FILHO, R. A força das ideias para um capitalismo sustentável. Barueri: Manole, 2014.

MAIO, M. C. Nem Rotschild nem Trotsky: o pensamento anti-semita de Gustavo Barroso. Rio de Janeiro: Imago Editora, 1992.

MAZZUCATO, M. The entrepreneurial state: debunking public vs. private sector myths. London; New York: Anthem Press, 2014.

MENDONÇA, Ricardo. Eleitor de Bolsonaro não leva suas opinióes ao pé da letra, diz estudo. Valor Econômico, São Paulo, 5 jun. 2017. Disponível em: <http://www.valor.com.br/politica/4992164/ eleitor-de-bolsonaro-nao-leva-suas-opinioes-ao-pe-da-letra-diz-estudo>. Acesso em: 16 set. 2018.

MIDIA LIVRE. Médicos Cubanos sáo vaiados por Médicos brasileiros em aeroporto. 2013. Disponível em: <http://folhacentrosul.com.br/geral/1693/medicos-cubanos-sao-vaiados-pormedicos-brasileiros-em-aeroporto>. Acesso em: 16 set. 2018.

MINISTÉRIO DA FAZENDA. Relatório sobre a Distribuiçáo Pessoal da Renda e da Riqueza da Populaçáo Brasileira - 2015. 2016. Disponível em: <http://www.fazenda.gov.br/centrais-deconteudos/publicacoes/transparencia-fiscal/distribuicao-renda-e-riqueza/relatorio-distribuicao-darenda-2016-05-09.pdf/view>. Acesso em: 16 set. 2018.

MUEL-DREYFUS, F. Vichy et l'éternel féminin: contribution à une sociologie politique de l'ordre des corps. Paris: Editions du Seuil, 1996.

MÜLLER, H.-P. Société, morale et individualisme. La théorie morale d'Emile Durkheim. Trivium [En ligne], v. 13, p. 1-25, 2013. URL : Disponível em: <http://trivium.revues.org/4490>. Acesso em: 2 abr. 2018.

ODILLA, Fernanda; PASSARINHO, Nathalia BARRUCHO, Luís. Como defender meritocracia quando Brasil é o país que menos taxa herança?, diz discípulo de Piketty. BBC Brasil, Londres, maio 2018. Disponível em: <https://www.bbc.com/portuguese/internacional-44020436>. Acesso em: 16 set. 2018.

O GLOBO. Economia. O homem que quebrou a Bolsa de Valores do Rio. 2012. Disponível em: <http://oglobo.globo.com/economia/o-homem-que-quebrou-bolsa-de-valores-do-rio-3609758>. Acesso em: 16 set. 2018.

OLIVEIRA, Ribamar. Secretário da Receita faz críticas à concentração da renda no Brasil. Valor Econômico, São Paulo, 10 maio 2017. Disponível em: <http://www.valor.com.br/brasil/4963232/ secretario-da-receita-faz-criticas-concentracao-da-renda-no-brasil >. Acesso em: 16 set. 2018. 
ONUBR. Brasil é paraíso tributário para super-ricos, diz estudo de centro da ONU. 2016. Disponível em: <https://nacoesunidas.org/brasil-e-paraiso-tributario-para-super-ricos-diz-estudode-centro-da-onu/>. Acesso em: 16 set. 2018.

PIKETTY, T. Le capital au XXIe siècle. Paris: Éd. du Seuil, 2013.

O capital no século XXI. Rio de Janeiro: Intrínseca, 2014 a.

Capital in the twenty-first century. Cambridge: Belknap Press, 2014b.

PINÇON, M.; PINÇON-CHARLOT, M. Tentative d'évasion (fiscale). Paris: Zones, 2015.

Sociologie de la bourgeoisie. Paris: la Découverte, 2016.

PAULANI, Lena; PASCOA, Airton. Dizem os pais. Folha de S. Paulo, São Paulo, 18 maio 2008. Disponível em: <https://www1.folha.uol.com.br/fsp/opiniao/fz1805200809.htm>. Acesso em: 16 set. 2018.

PIKETTY'S, Thomas. Is there anything more to rising wealth inequality than soaring property prices? The Economist, Londres, 17 jun. 2014. Disponível em: <http://www.economist.com/blogs/ freeexchange/2014/06/thomas-pikettys-capital>. Acesso em: 16 set. 2018.

ROMERO, Cristiano. A briga que ameaça o governo Lula. Valor Econômico, Especial, São Paulo, 14 set. 2005, p. A1, Disponível em: <https://www2.senado.leg.br/bdsf/bitstream/handle/ id/454733/noticia.htm?sequence=1>. Acesso em: 16 set. 2018.

RENAUT, Alain et al. Inégalités et justice sociale. In: BOLTANSKI, L.Croissance des inégalités, effacement des classes sociales? Paris: La Découverte, p. 25-47, 2014.

SALGADO, Eduardo. Por que a renda é tão desigual no capitalismo? Exame, São Paulo, 10 jul. 2014. Disponível em: <https://exame.abril.com.br/revista-exame/por-que-e-tao-desigual/>. Acesso em: 16 set. 2018.

SENADO NOTÍCIAS. Daniel Dantas afirma que havia interferências políticas em seus negócios. 2005. Disponível em: <https://www12.senado.leg.br/noticias/materias/2005/09/21/daniel-dantasafirma-que-havia-interferencias-politicas-em-seus-negocios>. Acesso em: 16 set. 2018.

SMITH, Noah. Piketty's Three Big Mistakes. Thomas Piketty's theory about income inequality has taken a triple hit from an MIT graduate student. 2015. Disponível em: <https://www.bloomberg. com/view/articles/2015-03-27/piketty-s-three-big-mistakes-in-inequality-analysis $>$. Acesso em: 16 set. 2018.

STEINBAUM, Marshall. Why Are Economists Giving Piketty the Cold Shoulder? Boston Rewiw, Cambridge, 12 maio 2017. Disponível em: <http://bostonreview.net/class-inequality/marshallsteinbaum-why-are-economists-giving-piketty-cold-shoulder\#>. Acesso em: 16 set. 2018.

TAUNAY, V. de. O encilhamento. São Paulo: Edições Melhoramentos, 1923.

TAVARES, Maria da Conceição. Globalitarismo e neobobismo. Folha de S. Paulo, São Paulo. 30 mar. 1997. Disponível em: <https://www1.folha.uol.com.br/fsp/1997/3/30/dinheiro/14.html>. Acesso em: 16 set. 2018. 
THE ECONOMIST. Inequality: Does raising all boats lift the tide? The Economist, Londres, mar. 2014.

THOMPSON, J. B. Political scandal: power and visibility in the media age. Cambridge: Polity Press, 2000.

TOLEDO, José Roberto de. 62\% apoiam cotas para alunos negros, pobres e da escola pública, diz Ibope. O Estadáo, São Paulo, 16 fev. 2013. Disponível em: <http://educacao.estadao. com.br/noticias/geral,62-apoiam-cotas-para-alunos-negros-pobres-e-da-escola-publica-dizibope,997758>. Acesso em: 16 set. 2018.

WITTGENSTEIN, L. Tractatus logico-philosophicus. London; New York: Routledge \& Paul; Humanities Press, 1961.

WRIGHT, Erik Olin; FRÉMEAUX, Nicolas. part 1. The Piketty effect. Disponível em: <http:// www.publicbooks.org/the-piketty-effect-part-1/>. Acesso em: 16 set. 2018.

\section{Hiding the '1\%': sociocultural critic and logic}

\section{Abstract}

Brazil is considered as one of the countries with the most uneven wealth distribution in the contemporary world. However, no specific social critic of material resources' assimetry emerges in the country. The paper discusses some hypotheses to explain this apparently illogical reality. It responds fundamentally based on path dependency for critical affirmation of cultural resources' assimetry and links it to the urgency of the main political groups which arose with the redemocratization of 1985 and whose political dispute dynamic follows a cultural logic. The cultural dispute encompass the potentially economic questions, because it installs itself in a durable manner as a metaphor system, endowed with "symbolic hardness".

Keywords: sociology of the intellectuals, sociology of finance, sociology of scandals, sociology of critics, social inequalities.

Recebido em: 18.05.2018

Aprovado em: 22.07.2018 